\title{
WUHAN: BACK TO THE FUTURE AND THE RETURN OF CORONAVIRUSES
}

\author{
Alfredo Ponce-de-León ${ }^{1 *}$, Arturo Galindo-Fraga ${ }^{2}$, Guillermo M. Ruiz-Palacios ${ }^{1}$, \\ AND JOSÉ SIFUENTES-OSORNIO ${ }^{3}$ \\ ${ }^{1}$ Departament of Infectology, ${ }^{2}$ Subdirectorate of Hospital Epidemiology and Quality Control of Medical Atention, and \\ ${ }^{3}$ Directorate of Medicine, Instituto Nacional de Ciencias Médicas y Nutrición Salvador Zubirán, Mexico City, Mexico
}

\section{INTRODUCTION}

On January 30, 2020, the World Health Organization Director-General declared that the outbreak of the 2019 new coronavirus (initially named 2019-nCoV, and currently known as SARS-CoV-2) constitutes a Public Health Emergency of International Concern ${ }^{1}$. This is the third CoV that emerges in this century causing human outbreaks and thought to arise from exposure to animals. As of February 17, 2020, the total number of cases worldwide ( 25 countries outside of China) is, globally, about 71,429 cases, 6198 in severe condition and 1669 deaths, with a fatality rate of $2.48 \%$ (data from the World Health Organization at https://www.who.int/emergencies/diseases/novelcoronavirus-2019/situation-reports/).

\section{Origin}

CoVs are enveloped RNA viruses widely distributed among humans, animals, and nature. Their genomes undergo frequent recombination. These two features and the increasing contact between animals and humans cause periodic outbreaks of cross-species infections. Four CoVs - 229E, OC43, NL63, and HKU1 cause common cold, while two more virulent strains,
SARS-CoV and MERS-CoV, may cause respiratory failure and death. Based on the current sequence databases, all human CoVs have animal origins: SARS-CoV, MERS-CoV, HCoV-NL63, and HCoV-229E have originated in bats; $\mathrm{HCOV}-\mathrm{OC} 43$ and $\mathrm{HCOV}-\mathrm{HKU} 1$ originated from rodents ${ }^{2}$. SARS-CoV-2 belongs to a $2 \mathrm{~B}-\mathrm{CoV}$ group; it is different to SARS-CoV, although they share approximately $80 \%$ of their genome. Initial comparisons have shown $99.9 \%$ conservation, suggesting a common and recent ancestor ${ }^{3}$. It seems that this virus uses the same receptor angiotensin-converting enzyme 2 (ACE-2) as SARS-CoV ${ }^{4}$. ACE-2 receptor is predominantly found in the lower respiratory tract, which may explain the relationship between these two viruses and pneumonia. Its nucleocapsid protein is highly conserved ( $90 \%$ identical to SARS-CoV), and thus, it may be used to detect antibodies to track down those patients exposed but that remained asymptomatic.

\section{Clinical features, diagnosis, and treatment}

Most patients with SARS-CoV-2 present the now called COVID-19 disease (from the acronym Coronavirus disease 2019), with fever and cough, but may
${ }^{*}$ Corresponding author:

Alfredo Ponce-de-León

E-mail: alf.poncedeleon@gmail.com
Received for publication: 11-02-2020

Approved for publication: 17-02-2020

DOI: $10.24875 / R I C .20000023$

0034-8376 / (c) 2020 Revista de Investigación Clínica. Published by Permanyer. This is an open access article under the CC BY-NC-ND license (http://creativecommons.org/licenses/by-nc-nd/4.0/). 
also show malaise, diarrhea, headache, sore throat, and dyspnea ${ }^{5}$. Cases in children are rare and very few cases have been reported in this population; the median age of those infected patients is 49 years. Most cases have been mild, but hospitalized patients show signs and symptoms of pneumonia with large lung infiltrates. Some patients develop acute respiratory distress syndrome and need intensive care, particularly those with comorbidities. Symptoms of COVID-19 are not specific, and the most important factor to suspect the infection is travel history to China, other regions affected or having had direct contact with a case. The incubation period varies between 2 and 14 days. Most reports show a mortality rate around $2 \%$. Until now, mortality seems to be associated with hypertension and diabetes, but is too soon to define more precisely all risk factors associated with this fatal outcome and very few cases have been reported in this population.

The diagnosis of COVID-19 is currently based on nucleic acid amplification techniques. Laboratory facilities have developed multiple PCR assays that can amplify several viruses. Perhaps, more important than to assure which virus is producing the infection is the ability of the method to rule out the diagnosis. Whole-genome sequencing has also provided important information. Definitive diagnosis still requires that clinical samples are sent to referral laboratories.

At present, there is no proven effective drug treatment for SARS-CoV-2. A controlled clinical trial was initiated with the nucleoside analog remdesivir that showed some activity in patients with MERS-CoV. In severe cases, advanced ventilatory management and intensive therapy support have been required. Most cases, with mild manifestations, only require symptomatic treatment.

\section{Molecular epidemiology: tracking down the epidemics and the future}

Perhaps, the most important and intriguing question to be resolved when a new infection breaks through is what is causing this set of infections. Since late
December, but perhaps earlier, it seemed probable that a new virus was causing severe cases of respiratory disease. The fast and reliable tools now available showed that this, in fact, was the case, and the Chinese Center for Disease Control and Prevention (China $C D C$ ) laboratories rapidly informed about the SARS-CoV-2 as the causative agent.

The next set of questions, in turn, may be even more difficult to answer as explained before, i.e., is there a common link between cases? Is this a human pathogen or is it associated to other reservoirs? And, if human-to-human transmission is the main route, how fast is it spreading? Are there super-spreaders as noted in the first SARS-CoV outbreak? To answer these questions, both conventional epidemiologic studies and molecular tools are needed. As discussed before, this virus is adapted to humans, perhaps more linked to bat CoVs; nevertheless, although detecting sequences of this virus in the environment of a seafood market was important, intermediate hosts cannot be ruled out (pangolin was suspected to be involved in this CoV infection).

Until this point, although there still is some debate about which is the best mode of transmission, contact, aerosols, droplets, or a combination of these, the intrinsic dynamics and the modeling that have been carried out have shown that the basic reproductive number for SARS-CoV-2 is $2.68(95 \% \mathrm{Cl} 2.47-2.86)$ and that the epidemics doubling time is 6.4 days (95\% Cl 5.8-7.1) ${ }^{6}$.

This is extremely helpful information since it shows that considerable effort to stop the epidemic within China and worldwide will be needed.

\section{Mexico and SARS-CoV-2}

In Mexico, since it was observed that the virus has an important transmissibility, the Ministry of Health convened an expert group to update the protocols to face a pandemic and adjust them to the SARS-CoV-2. The protocols for the identification of travelers with suspected infection, contact follow-up and case studies, as well as the standardization of the diagnostic test and its validation in different centers have been established. There is a call center for the attention of the 
population, case registration, home delivery for the sampling of mild cases, and the reference of patients potentially complicated to specialized centers ${ }^{7}$.

\section{REFERENCES}

1. World Health Organization. Statement on the $2^{\text {nd }}$ Meeting of the International Health Regulations. Emergency Committee Regarding the Outbreak of Novel Coronavirus (2019-nCoV); 2005. Available from: https://www.who.int/news-room/ detail/30-01-2020-statement-on-the-second-meeting-of-theinternational-health-regulations-(2005)-emergency-committee-regarding-the-outbreak-of-novel-coronavirus-(2019-ncov). [Last accessed on 2020 Feb 04 2020].
2. Cui J, Li F, Shi ZL. Origin and evolution of pathogenic coronaviruses. Nat Rev Microbiol. 2019;17:181-92.

3. Gralinski LE, Menachery VD. Return of the Coronavirus: 2019 nCoV. Viruses. 2020;12:e135.

4. Lu R, Zhao X, Li J, Niu P, Yang B, Wu H, et al. Genomic characterization and epidemiology of 2019 novel coronavirus: implications for virus origins and receptor binding. Lancet. Jan 292020 [Epub ahead of print].

5. Chen N, Zhou M, Dong X, Qu J, Gong F, Han Y, et al. Epidemiological and clinical characteristics of 99 cases of 2019 novel coronavirus pneumonia in Wuhan, China: a descriptive study. Lancet. Jan 292020 [Epub ahead of print].

6. Li Q, Guan X, Wu P, Wang X, Zhou L, Tong Y, et al. Early transmission dynamics in Wuhan, China, of novel coronavirus-infected pneumonia. N Engl J Med 2020. Jan 292020 [Epub ahead of print].

7. de Salud S. Nuevo Coronavirus: información General Sobre el "Nuevo Coronavirus", Published on Jan 31 st 2020. Available from: https://www.gob.mx/salud/documentos/nuevo-coronavirus. [Last accessed on 2020 Feb 04 2020]. 